\title{
The Federal Science Project: A Scientist in Every Classroom
}

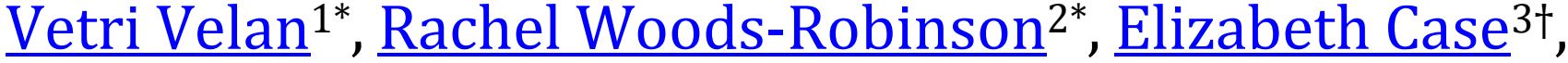 Isabel Warner ${ }^{4 \dagger}$, Andrea Poppiti $^{5}$, Brian Abramowitz $^{6}$}

${ }^{1}$ University of California, Berkeley, Department of Physics, Berkeley, California

2University of California, Berkeley, Applied Science and Technology Graduate Group, Berkeley, California

${ }^{3}$ Columbia University, Department of Earth and Environmental Sciences, New York City, New York

${ }^{4}$ University of Queensland, Institute for Molecular Bioscience, Brisbane, Queensland, Australia

${ }^{5}$ Rutgers University, Graduate School of Education, New Brunswick, New Jersey

6University of Florida, College of Education, Gainesville, Florida

$*, \dagger$ Indicates equal contributions

https://doi.org/10.38126/ISPG180308

Corresponding author: vvelan@berkeley.edu, rwoodsrobinson@berkeley.edu

Keywords: K12 education; outreach; STEM

Executive Summary: The United States urgently needs science-based solutions for a multitude of policy issues, and a basic societal understanding of science is essential to gaining public trust and addressing these issues. However, there is a disconnect between professional scientists and engineers and K-12 science education. Many students will graduate after 13 years of school having never met a scientist. This missed opportunity is not an issue of supply. There are over 7 million practicing scientists and engineers in the U.S.; if every scientist spent just one hour a year in a classroom, each student would get at least three visits from a scientist every single year. Here, we propose the Federal Science Project: a federally funded, nationwide program to bring scientists into all K12 schools across the U.S. with the goal of reaching every student, regardless of geographic location. Scientists and engineers across disciplines and sectors would undergo training in communication skills and cultural competency, connect with classrooms via a national database with support from full-time staff, partner with teachers to deliver interactive lessons aligned with existing curriculum and standards, and receive appropriate compensation. Close partnerships between scientists, engineers, teachers, policymakers, and community partners in science education (science centers, museums, etc.) would invigorate the trust-based connections needed for 21st-century science education and policy transformations.

\section{Introduction and motivation}

The coming century demands urgent action by the United States on a vast array of scientific policy issues. From climate change and artificial intelligence to antibiotic resistance and the increased dangers posed by infectious diseases, the most pressing questions will require a societal "culture of familiarity" with science. This culture empowers individuals and communities to make informed decisions around lifestyle, purchases, and policies
(McCaffrey 2012). However, the American public is generally deeply uninformed about, or even antagonistic toward, science and scientists (Fleming 2020; Ferguson 2020; Hmielowski 2013; Funk 2020). Nearly $75 \%$ of U.S. adults fail basic science literacy assessments (Hobson 2008). Meanwhile, many scientists and engineers ${ }^{1}$ are disconnected from the education system they have benefitted from. For example, a 2012 analysis found only 32\%

\footnotetext{
${ }^{1}$ For brevity, we will use "scientist" to refer to a practicing scientist or engineer, whether in industry, academia, or government.
} 
of biologists and physicists participate in $\mathrm{K}-12$ outreach (Ecklund 2012).

To create a culture of familiarity with science, federal policymakers should establish the Federal Science Project (FSP): a nationwide program that connects practicing scientists with $\mathrm{K}-12$ students. A program of this size and scope would impact a generation of students, teachers, and scientists, while addressing key challenges in K-12 education and inspiring connections and partnerships necessary for equitable science solutions.

Science literacy is a long-term challenge that starts in the K-12 classroom. In Science, The Endless Frontier, Vannevar Bush believed there should "be no ceilings, other than ability itself, to intellectual ambition... every boy and girl shall know that, if [they show] that [they have] what it takes, the sky is the limit" (Bush 1945). Yet, 75 years after Bush's report, factors other than "intellectual ambition" continue to severely limit access to scientific education and careers. First, many students lack access to quality Science, Technology, Engineering, and Mathematics (STEM) education (JEC 2012), particularly students from immigrant groups and Title 1 schools (schools in which at least $40 \%$ of students are from low-income households). "Inquiry-based" science education, grounded in hands-on experiments and asking questions, correlates to higher test scores and deeper long-term science literacy, but it is still not commonplace in the classroom (Scott 2013). In addition to limited access to materials and methods, students lack access to science role models. Thus, many K-12 students lack exposure to what it means to be a scientist, encouragement to pursue science, knowledge that science is a viable career option, or even the ability to see themselves as scientists. The physical sciences are especially dominated by white men, and the stereotypical image of scientists in the media is a white man (Miller 2018; Funk 2018). Notably, fewer Black and Latino/a/x students are pursuing STEM degrees than 20 years ago (RiegleCrumb 2019). Even many students who show positive feelings toward scientific inquiry do not necessarily want to become scientists themselves (DeWitt 2011). Finally, access to scientists tends to be concentrated in communities near universities, national labs, and scientific industries, creating a proximity bias in childhood exposure to science and scientists.
Despite the impact of science role models on $\mathrm{K}-12$ students, scientists lack career incentives to connect with K-12 schools. For example, in academia, publications and funding remain the primary criteria for advancement, while mentorship and outreach are secondary (Woolston 2018). In fact, there are many disincentives. Outreach programs connecting scientists with $\mathrm{K}-12$ classrooms usually operate on a volunteer extracurricular basis, meaning participating scientists often need to take time away from professional and/or personal responsibilities, like research or caretaking. Moreover, many grants and workplaces forbid "time off" for outreach, or outreach is dismissed by principal investigators (PIs) as "a waste of time" (Cerrato 2018). Even when scientists are committed to outreach, many institutions lack the infrastructure to build outreach programs, connections with existing outreach groups, and/or training on how to succeed in a classroom. The aforementioned analysis of biologists and physicists (Ecklund 2012) found that approximately one third of respondents cited their institutions as a barrier to science outreach. In addition, certain fields and demographics are more likely to engage with science education, influencing the perception and career impact of outreach (Johnson 2014, Woolston 2018). All these aspects fuel the disconnect between scientists and science education, with no national network of sustainable, long-term, or long-range mechanisms to build relationships between scientists and communities.

A nationwide program to connect scientists with teachers and schools would be an entry point to address some of these challenges. Importantly, this pursuit is not limited by the number of scientists. In fact, the supply exceeds demand. In the U.S., there are over 7 million practicing scientists and engineers, including those in industry, academia, and government (Sargent 2017), and approximately 56.6 million K-12 students (Bustamante 2019). Using a conservative average classroom size of 25 students (NCES 2012), this amounts to 2.3 million classrooms. If each scientist spent just one hour per year in a classroom to teach an interactive lesson, every single K-12 student would get at least three scientist visits each year.

Thus, the challenge is twofold: first, to commit resources to improving science education in America, and second, to distribute these resources. In 
this paper, we outline how and why the U.S. should establish a national program to connect scientists with teachers and classrooms across the country.

\section{Proposed policy}

Existing programs that connect scientists to $\mathrm{K}-12$ students range from single-scientist-visits to longterm teacher-scientist partnerships. Programs may run during or after school, as summer camps or extracurriculars, and can bring scientists to classrooms ("scientists-in-schools" model) or bring students to labs or into the field. In this policy proposal, the goal is to build and support infrastructure to enable single-visit "scientists-inschools" experiences. However, the intention is that these interactions and infrastructure create a gateway for longer-term relationships between scientists, classrooms, and communities.

The key task of the FSP is to connect every K-12 classroom with at least one practicing scientist every year. This connection could be implemented as a career talk, lesson, experiment, mentorship, or any activity that introduces students to the day-to-day work of a scientist. This goal requires a significant policy shift and could be accomplished in several ways. We focus first on the criteria that any policy framework should include, then propose a specific policy and discuss alternatives.

Drawing from peer-reviewed literature (Figure 1) and lessons learned from existing programs, we propose that the FSP satisfy the following criteria:

1. The program must involve and empower all stakeholders. It must account for the complexity of the U.S. education system, where the federal government, state legislatures, local school boards, and community members are all substantial partners. Scientists and teachers must both feel empowered to promote science literacy in ways that best match their communities. An outreach program cannot feel like a government command, and it must actually address educational standards.

2. The cost to individual teachers and school districts must be \$0. Otherwise, the program will exacerbate existing inequities in scientific exposure.

3. Scientists must be appropriately incentivized to participate, all costs must be reimbursed, and the barrier-to-entry must be low. The most straightforward legislative solution would be financial stipends for participation, and a set of federal research grants only open to program participants. Other policies could be implemented by university departments, professional societies, or companies, but these are difficult to legislate. Reimbursed costs include travel expenses, experimental equipment, and time away from job responsibilities. In addition, specific awards, recognized and weighted on federal grant applications, could be established. State agencies could also choose to count hours toward teaching accreditation or similar certifications.

4. Participating scientists must receive outreach training and be reimbursed for the time spent in training. Typical training provided to scientists by academic programs is insufficient for the communication and cultural competency skills necessary for K-12 outreach (Ecklund 2012). Training could range from an online course to public speaking workshops, and it should be led by paid experts.

5. There must be a well-managed, easilyaccessible central hub for scientists to connect to educators, and vice-versa. This is to reduce the onus on both groups and to ensure they are able to find compatible partners. Our proposed strategy is a national database of scientists managed by the Department of Education and regional staff; a collection of lesson plans and materials for scientists to use, and a robust effort to reach teachers, especially those in underserved communities and far from academic hubs. Federal funds should be appropriately allocated to build and maintain this infrastructure.

6. The program must be regularly assessed. The program should face review to ensure that funds are spent effectively and that stakeholders are actually receiving benefits (Figure 1). Successes and areas for improvement should be identified and appropriately addressed. 


\section{IMPACTS OF SINGLE-VISIT STEM LESSONS}

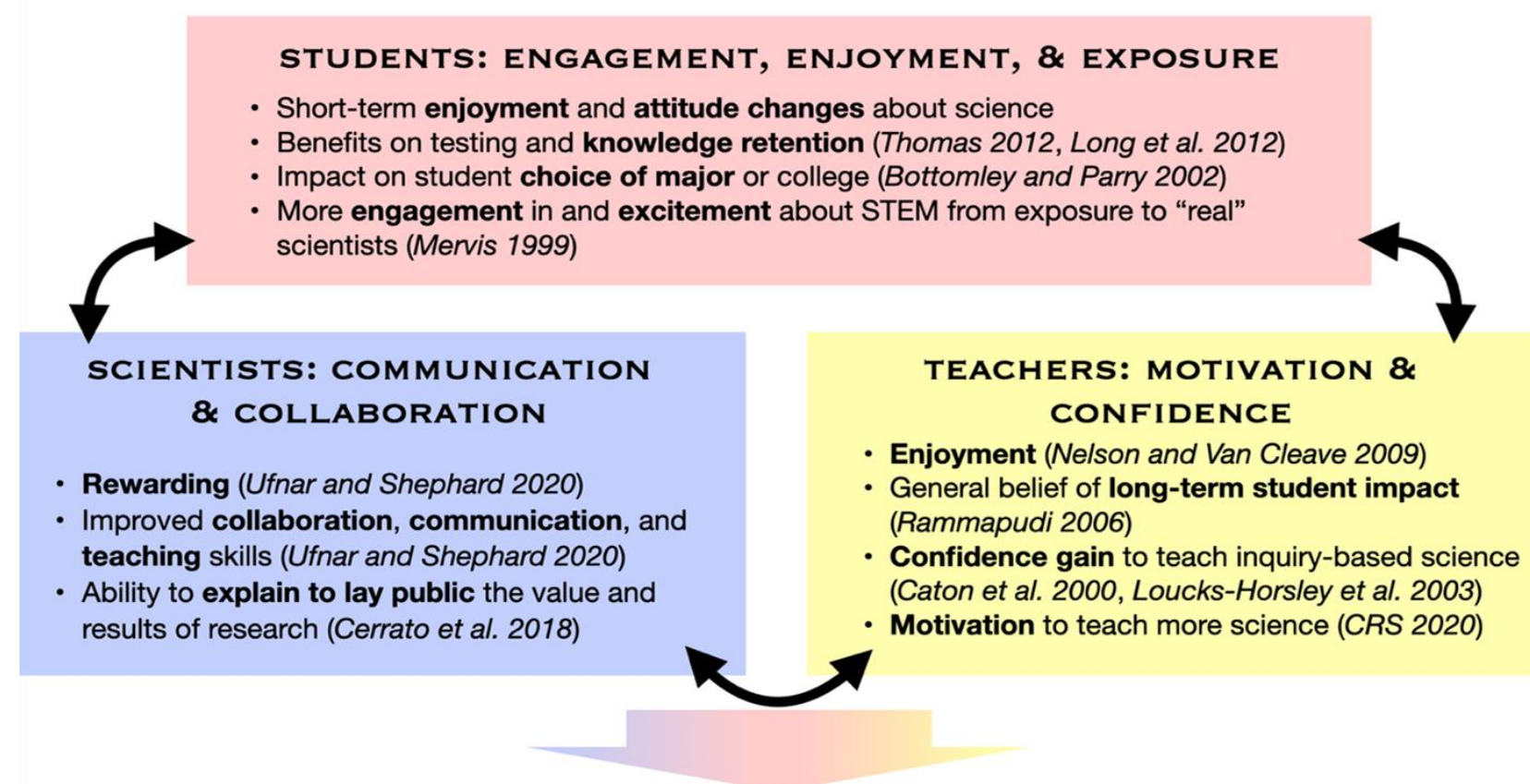

IMPACTS ON SOCIETY

Figure 1: Key impacts of single-visit "scientists-in-schools" programs from the peer-reviewed literature. Citations are specified in the graphic.

The policy we propose to achieve these goals is distributing federal block grants to states. The U.S. Department of Education could fund states to implement a universal STEM outreach program in their jurisdictions. Each state would be required to meet the criteria above, but otherwise would have the ability to structure programs as best fit residents' needs. A program of this magnitude would benefit from a "trial run," where selected districts in a few states test the program and determine successes and challenges. Existing programs have established a successful precedent for scale-up, starting with districts that cover a diverse set of students and geographies (University of Florida 2021).

Although exact costs are difficult to calculate without more detail, a reasonable estimate suggests a lowcost relative to the projected impact of 2.3 million annual classroom visits. Travel and lesson materials will likely cost between $\$ 0$ (for virtual lessons) to

$\$ 100^{2}$. An administrative cost of $\$ 100 /$ visit will support salaries of state- and federal-level coordinators, as well as district-level expenses; for example, many schools require visitor background checks and liability insurance. Assuming a stipend to each scientist of $\$ 100 /$ visit, total costs add up to $\$ 200-\$ 300 /$ visit, bringing total annual costs of this program to $\$ 660$ million or less. This is less than $0.3 \%$ of the combined $\$ 219$ billion spent by the federal government annually on K-12 education, scientific research, and technology development (U.S. Census 2018; Hourihan 2021).

\begin{tabular}{|l|l|}
\hline Item & Cost/visit \\
\hline $\begin{array}{l}\text { Travel and lesson } \\
\text { materials }\end{array}$ & $\$ 0-100$ \\
\hline $\begin{array}{l}\text { Program } \\
\text { administration }\end{array}$ & $\$ 100$ \\
\hline Stipend to scientist & $\$ 100$ \\
\hline Total per visit & $\$ 200-300$ \\
\hline Annual visits & 2.3 million \\
\hline Annual total cost & $\$ 460-690$ million \\
\hline
\end{tabular}

Table 1: Estimated cost of the Federal Science Project.

\footnotetext{
${ }^{2}$ At the IRS rate of $\$ 0.56 /$ mile (IRS 2020), a 50-mile round trip would cost $\$ 56$, and equipment costs of $\$ 44 /$ visit are reasonable since scientists may already have supplies that can be reused.
} 
Other policies to ensure a "scientist in every classroom" could include mandating outreach as a condition of federal grants or creating fellowships for scientists to do outreach full-time after graduation (similar to AmeriCorps). While these are reasonable models, there are drawbacks to each. These models risk inequitable distribution of scientists across states and high turnover of scientists in fixed term roles. Mandated outreach is similar to the NSF Broader Impact goals, which are difficult to measure and require significant administrative work from scientists. Fellowships could still be possible under the proposed block-grant system but would be determined by the state administration. A mobile corps of full-time scientists may provide an important reservoir for states with fewer scientists and help facilitate personnel exchange across state borders.

\section{Existing "scientist-in-a-classroom" outreach programs and their societal impacts}

Thousands of successful "scientist-in-a-classroom" programs already exist in the U.S. and internationally to draw inspiration and experience from, ranging from small nonprofits to large university endeavors. The goal of our proposal is not to reinvent or replace these efforts, but to support and expand their missions by connecting resources and facilitating more long-lasting scientist-classroom-community interactions.

A key challenge of assessing the impacts of shortterm visits as standalone events is that their goals are long-term and societal, which are inherently difficult to quantify (Laursen 2017). However, as summarized in Figure 1, the research literature shows overwhelmingly positive benefits to the three key stakeholders: scientists, teachers, and students. The key positive impacts are on student learning and views about science, on teachers' expertise and confidence, and on scientists' ability to communicate effectively (Laursen 2017).

\section{i. Insight from the "Scientist in Every Florida School" program}

One example of a wide-reaching single-visit program that can serve as a blueprint for the FSP is "Scientist in Every Florida School" (SEFS), which aims to bring an earth-systems scientist to every public school in Florida (University of Florida 2021). The program is funded by private philanthropy and the University of Florida, and it offers a state-level pilot of the FSP that merges outreach programs on a large scale. During the 2020-21 school year, SEFS has created 54,000 student impressions ${ }^{3}$ by reaching schools in $60 \%$ of Florida's sixty-seven counties through more than 1,700 completed scientist classroom visits. Due to the COVID-19 pandemic, 99\% of the physical scientist classroom interactions were virtual to adhere to safety guidelines. However, this created an opportunity to reallocate resources and scale to support additional counties. Although there is no substitute for in-person scientist-student experiences, adding capacity for virtual visits allows programs to reach more students, and a similar approach may be taken with the FSP.

The SEFS program's priorities are supporting new teachers, providing resources for Title I schools, and preparing communities for environmental changes. With over 500 scientist volunteers, teachers request experts to help with particular science standards and serve as role models. Each scientist has received science communication training, including a course covering evidence-based communication strategies and logistics. The SEFS team consists of two former teachers who serve as logistical coordinators. Teachers' requests are processed by these coordinators to consider grade level, content, as well as other factors (scientists' identities, bilingual abilities, whether they are first-generation college attendees, etc.), and then notify a scientist who is a strong match. If the scientist is available and interested, the coordinator will send an introduction email to continue the planning process collaboratively and ensure both the scientist's and the teacher's visions for the interaction are aligned. Following the visit, a feedback form is distributed to both parties to assess the interaction and continue to improve the program.

The impact of SEFS has been measured primarily through qualitative and mixed-method approaches. These include interviews, focus groups, and district leader, teacher, and student testimonials. SEFS has reached $49 \%$ of the schools in the Palm Beach County

\footnotetext{
${ }^{3}$ The term "impressions" is used to quantify scientist-student interactions because sometimes a teacher would request multiple visits from the same scientist, and thus in some cases the same student is counted more than once.
} 
School district (tenth largest in the U.S.) where Science District Leader Jennifer Davis shared:

"The scientists' excitement and passion for their work engages the students like no other learning experience can. The students see real science happening, and they also get to see that these kinds of meaningful careers are firmly within their reach too!"

Forthcoming data will explore scientist-teacher educational partnerships as well as teacher and students' science conceptual changes as a result of a scientist classroom visit. While teachers have the option for just a single visit, they are supported to develop longer-term relationships with their matched scientist(s). So far, this model has resulted in lasting, collaborative, community partnerships.

\section{ii. Other programs in the United States}

Another example is the "Bay Area Scientists Inspiring Students" initiative, led by Community Resources for Science and serving Berkeley, California and the surrounding area, which annually connects 600 scientists to over 43,000 students (CRS 2020). This nonprofit works with scientists to create hour-long lesson plans, advertises those plans to teachers, and matches interested teachers with corresponding scientists. Similarly, industry projects like SunPower's "Horizons Solar Education" have brought industry mentors and hands-on lessons to over 30,000 students, free of cost to school districts (SunPower 2021).

Many similar programs are centered at universities and companies across the country, but they are generally disconnected from one another. Non-local outreach programs like "Skype a Scientist" and "Letter to a Pre-Scientist" offer examples of how to connect scientists with classrooms through online or postal interfaces. However, these existing outreach programs typically rely on short-term grants or donations; thus, they are vulnerable to funding shortfalls. In addition, these programs usually put the onus on teachers to actively seek out visits from scientists.

\section{iii. Federal funding models}

Federal funding for "scientist-in-a-classroom" visits has a precedent in the National Science Foundation (NSF) Graduate Teaching Fellows in K-12 Education
(GK-12) program, which ran from 1999-2011 (Ufnar 2012). It funded graduate students to undergo education training, partner with teachers, and conduct outreach for a year or more. As shown in Figure 2, programs were funded across the U.S., but, as with most outreach programs, the associated resources were clustered around major institutions, neglecting a sizable portion of American students. South Dakota received no fellowship funds, and Iowa, Wyoming, Alaska, Utah, and Nevada received just one each.

The FSP could be funded similarly to GK-12 and pay graduate students as outreach fellows. However, this model may exacerbate existing inequalities in STEM. In GK-12, institutions were funded through a grant competition, compounding existing resource distribution issues. Also, although successful in reaching many students, GK-12 unexpectedly lost all funding in 2011, and many programs were dissolved and never reinstated (Ufnar 2012). Thus, a longterm, sustainable funding structure is a requirement for these programs to succeed.

It is important to note that federally funded programs similar to the FSP have been implemented in other countries, with huge successes. For example, in Australia, the nationwide "STEM Professionals in Schools" program is federally funded and facilitates partnerships between schools and industry to bring STEM professionals into classrooms (CSIRO 2021). The U.S. must adopt and invest in a similar program to maintain its status as a world leader in scientific, technological, and economic innovation.

\section{Challenges}

The policy of establishing the FSP faces a number of logistical challenges and will require support to enable large cultural shifts in science education.

First, there is the matter of funding. Federal block grants have many advantages, most notably empowering states to address specific challenges within their education systems. However, there is precedent for states to refuse federal aid or demand waivers to spend funds elsewhere (NFIB v. Sebelius 2012). In addition, running the bulk of this program at the state level could lead to inequities between states; some states are relatively "scientist-poor" and others are "scientist-rich". Addressing this discrepancy will require federal intervention to allow for resource exchanges (i.e., scientists and 


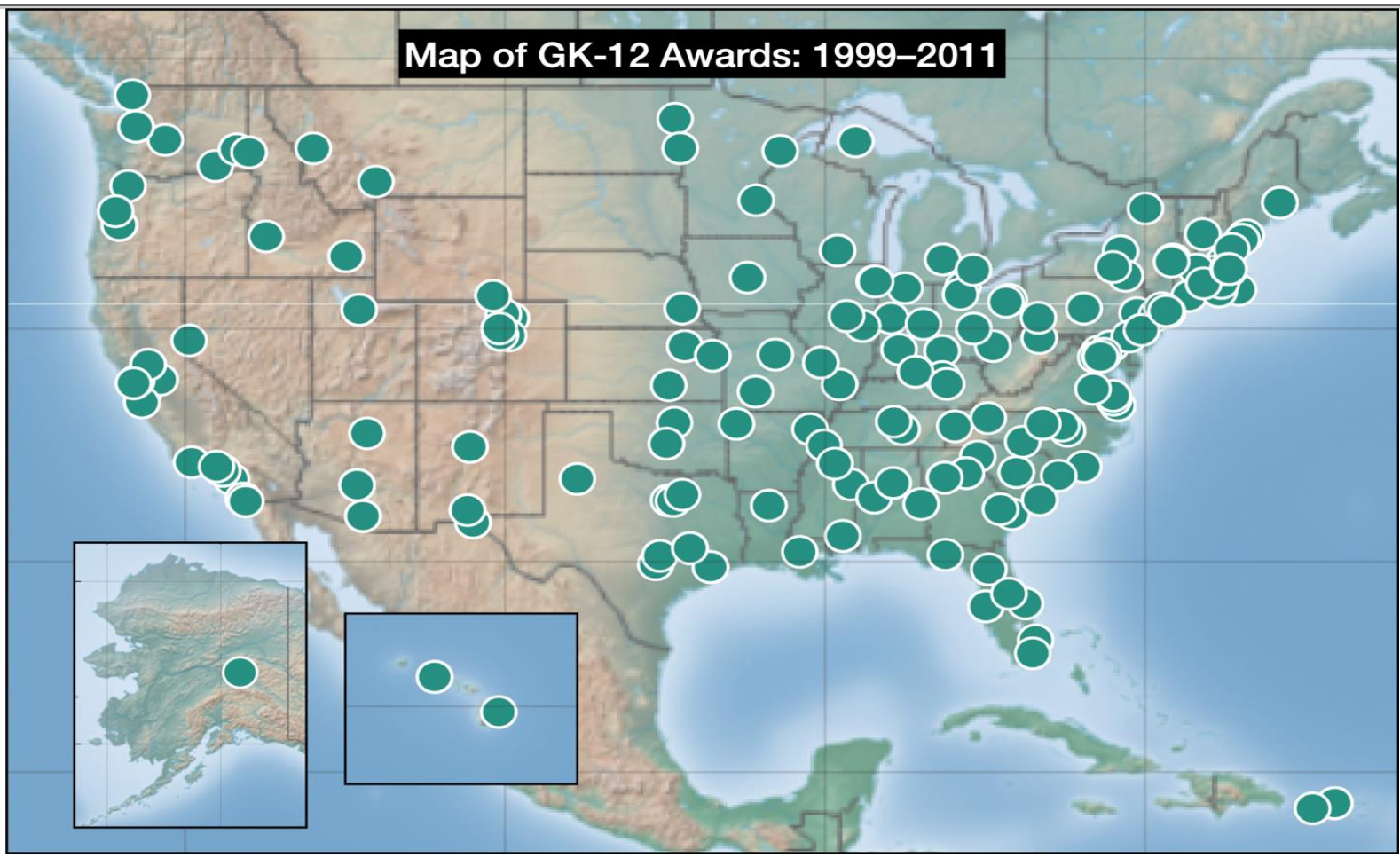

Figure 2: NSF GK-12 funded "scientists-in-schools" outreach projects, 1999-2012. Project sites are located near academic hubs, representative of where most STEM outreach resources are concentrated.

funds) across state borders. An additional challenge is ensuring that funds are long-term and sustainable and will not be abruptly discontinued like GK-12. While the exact expenditure on these programs will depend on the congressional budget process, the establishment of a formal framework under the Department of Education will help cement the program and its funding for the long term. This would include permanent staff, branding, and publicity efforts to promote popular support for the program.

Similarly, the logistics of executing this program are complex and multifaceted, requiring permanent staff in every state, the creation of a national database of scientists and materials, coordinated outreach to schools in every county, and the education of scientists on pedagogy and cultural competency. There are logistical issues to visits from scientists, as well. To reach rural or remote areas that are not well connected to universities or industry, scientists may have to travel significant distances, which can be tiring, costly, and prohibitive, especially for those with familial care and other commitments. Virtual visits, combined with hands-on lessons that can be shipped to schools, may alleviate this challenge.
Furthermore, the FSP must be structured such that outreach duties do not further burden underrepresented groups, historically the most motivated to pursue culture change (the so-called "minority tax") (Coe 2019).

Additionally, some communities distrust outsiders and institutions; without first developing trust-based relationships rooted in equity, single-visits risk propagating harm, hampering science communication, and even endangering scientists. To mitigate this issue, we can look to examples like those set by the National Center for Science Education, which trains teachers who teach controversial issues like climate change and evolution (NCSE 2020). Long-term programs, focused on building these relationships at both the community and individual level, will be key to establish trust and ensure success, especially when teaching difficult or controversial topics. This type of partnership can take many forms, including taking community members on lab tours, participating in inclusive community events, and otherwise exposing scientists and the community to one another as human beings first. Extra incentives (financial and otherwise) and partnerships with public resources 
like museums and libraries may be necessary to build trust between the community and scientists. In addition, special funding and outreach from diverse scientific communicators will be needed to address historically excluded areas or groups (Dawson 2018; O'Boyle 2019). Assessing the impacts of these programs will be critical to identifying and properly addressing community needs over time, and metrics for success should be continuously evaluated and updated.

\section{Prospective}

The FSP has the potential to transform how science and engineering are seen in society. It follows the pattern of other historical large-scale efforts to transform an industry. For example, through the Work Projects Administration, President Franklin Roosevelt launched "The Federal Music Project" in 1938, bringing 225,000 performances to over 150 million Americans across the entire country and reinvigorating a passion for the arts (Bindas 2003). This endeavor sought to engage and employ musicians recovering from the Great Depression, and to make music accessible to Americans who otherwise would not be exposed to live concerts and music education. Following suit, the FSP will engage scientists and make science education and careers accessible to all Americans.

Even as scientific progress accelerates, the global issues America faces in the twenty-first century require policies based in widespread societal understanding of, and national collaboration through, science. These long-term challenges require "all-hands-on-deck" solutions. In 1945, in the face of a similar landscape, Vannevar Bush emphasized the importance of bolstering universities. Today, we propose the logical next step of his "Endless Frontier" vision: creating a strong pipeline of scientists and scientifically literate citizens, starting at a young age and encompassing the entire country. The FSP will inspire students, scientists, classroom teachers, and ultimately society at large, as we come together to build a more equitable and sustainable world.

\section{References}

Bindas, Kenneth J. All of This Music Belongs to the Nation: The WPA's Federal Music Project and American Society. Univ. of Tennessee Press, 2003.

Bush, Vannevar. "Science, The Endless Frontier." Director of the Office of Scientific Research and Development, United States Government Printing Office, Washington (1945).

https://www.nsf.gov/od/lpa/nsf50/vbush1945. $\underline{\mathrm{htm}}$

Bustamante, Jaleesa. "K-12 School Enrollment \& Student Population Statistics.” EducationData.org. (2019). https://educationdata.org/k12-enrollmentstatistics

Cerrato, Simona, Valentina Daelli, Helena Pertot, and Olga Puccioni. "The public-engaged scientists: Motivations, enablers and barriers." Research for All 2, no. 2 (2018): 313-322.

https://doi.org/10.18546/RFA.02.2.09

Coe, Imogen R., Ryan Wiley, and Linda-Gail Bekker "Organisational best practices towards gender equality in science and medicine." The Lancet 393, no. 10171 (2019): 587-593.

https://doi.org/10.1016/S01406736(18)33188-X

Commonwealth Scientific and Industrial Research Organisation (CSIRO). "STEM Professionals in Schools." (2021).

https://www.csiro.au/en/education/programs/ stem-professionals-in-schools
Community Resources for Science (CRS). "Bay Area Scientists Inspiring Students (BASIS)." (2020). https://crscience.org/outreach/basis/

Dawson, Emily. "Reimagining publics and (non) participation: Exploring exclusion from science communication through the experiences of lowincome, minority ethnic groups." Public Understanding of Science 27, no. 7 (2018): 772786. https://doi.org/10.1177/0963662517750072

DeWitt, Jennifer, Jonathan Osborne, Louise Archer, Justin Dillon, Beatrice Willis, and Billy Wong. "Young Children's Aspirations in Science: The unequivocal, the uncertain and the unthinkable." International Journal of Science Education, 35:6, 1037-1063 (2011). https://doi.org/10.1080/09500693.2011.60819 7

Ecklund, Elaine W., Sarah A. James, and Anne E. Lincoln. "How Academic Biologists and Physicists View Science Outreach." PLOS One 7(5): e36240 (2012). https://doi.org/10.1371/journal.pone.0036240

Ferguson, Sarah L., and Stephanie M. Lezotte. "Exploring the state of science stereotypes: Systematic review and meta-analysis of the Draw-A-Scientist Checklist." School Science and Mathematics 120, no. 1 (2020): 55-65. https://doi.org/10.1111/ssm.12382 
Fleming, Whitney, Adam L. Hayes, Katherine M. Crosman, and Ann Bostrom. "Indiscriminate, Irrelevant, and Sometimes Wrong: Causal Misconceptions about Climate Change." Risk Analysis 41, no. 1 (2021): 157-178.

https://doi.org/10.1111/risa.13587

Funk, Cary, Alec Tyson, Brian Kennedy, and Courtney Johnson. "Science and scientists held in high esteem across global publics." Pew Research Center. (2020).

https://www.pewresearch.org/science/2020/0

9/29/science-and-scientists-held-in-highesteem-across-global-publics/

Funk, Cary and Kim Parker. "Diversity in the STEM workforce varies widely across jobs." Pew Research Center. (2018).

https://www.pewresearch.org/socialtrends/2018/01/09/diversity-in-the-stemworkforce-varies-widely-across-jobs/

Hmielowski, Jay D., Lauren Feldman, Teresa A. Myers, Anthony Leiserowitz, and Edward Maibach. "An attack on science? Media use, trust in scientists, and perceptions of global warming." Public Understanding of Science 23, no. 7 (2014): 866883.

https://doi.org/10.1177/0963662513480091

Hobson, Art. "The surprising effectiveness of college scientific literacy courses." The Physics Teacher 46, no. 7 (2008): 404-406.

https://doi.org/10.1119/1.2981285

Hourihan, Matt. "A Primer on Federal R\&D Budget Trends." American Association for the Advancement of Science. (2021) https://www.aaas.org/sites/default/files/202102/AAAS $\% 20 \mathrm{R} \% 26 \mathrm{D} \% 20$ Primer $\% 20$ Update $\% 2$ 02021.pdf

Internal Revenue Service (IRS). "IRS issues standard mileage rates for 2021." (2020). https://www.irs.gov/newsroom/irs-issuesstandard-mileage-rates-for-2021

Johnson, David R., Elaine Howard Ecklund, and Anne E. Lincoln. "Narratives of science outreach in elite contexts of academic science." Science Communication 36, no. 1 (2014): 81-105. https://doi.org/10.1177/1075547013499142

Joint Economic Committee (JEC), U.S. Congress. "STEM Education: Preparing for the Jobs of the Future." (2012).

https://www.jec.senate.gov/public/index.cfm/d emocrats/2012/4/jec-releases-new-report-oneconomic-impact-of-stem-education
Laursen, Sandra, Carrie Liston, Heather Thiry, and Julie Graf. "What good is a scientist in the classroom? Participant outcomes and program design features for a short-duration science outreach intervention in $\mathrm{K}-12$ classrooms." CBE-Life Sciences Education 6, no. 1 (2007): 49-64. https://www.lifescied.org/doi/full/10.1187/cbe $.06-05-0165$

Long, Gary L., Carol A. Bailey, Barbara B. Bunn, Carla Slebodnick, Michael R. Johnson, Shad Derozier, Susanne M. Dana, and Julie R. Grady. "Chemistry Outreach Project to High Schools Using a Mobile Chemistry Laboratory, ChemKits, and Teacher Workshops." Journal of Chemical Education 89, no. 10 (2012): 1249-1258. https://pubs.acs.org/doi/abs/10.1021/ed20018 $\underline{5 e}$

Loucks-Horsley, Susan, Katherine E. Stiles, Susan Mundry, Nancy Love, and Peter W. Hewson. Designing professional development for teachers of science and mathematics. Corwin press. (2009).

McCaffrey, Mark and Joshua Rosenau. 2012. "Science Literacy Still Matters." Nature Climate Change 2, 636 (2012). https://doi.org/10.1038/nclimate1644

Mervis, Jeffrey. "Grad students head to class as new NSF teaching fellows." Science 286, 5441 (1999): 895895.

Miller, David I., Kyle M. Nolla, Alice H. Eagly, and David H. Uttal. "The development of children's genderscience stereotypes: a meta-analysis of 5 decades of US draw-a-scientist studies." Child development 89, no. 6 (2018): 1943-1955.

https://doi.org/10.1111/cdev.13039

National Center for Education Statistics (NCES), Schools and Staffing Survey. "Public School Teacher Data File, 2011-12." (2012).

https://nces.ed.gov/surveys/sass/tables/sass11 $122013314 \mathrm{t} 1 \mathrm{~s}$ 007.asp

National Center for Science Education (NCSE). "Breaking Down Barriers." (2020).

https://ncse.ngo/breaking-down-barriers

National Federation of Independent Business (NFIB) v. Sebelius. Supreme Court of the United States, 567 U.S. 519. (2012).

Nelson, Amy G. and Scott Van Cleave. "Energy Connections: Teacher Survey Report. St. Paul, MN." Science Museum of Minnesota's Department of Evaluation and Research in Learning. (2009).

O'Boyle, Sean. "How activists make science communication better." Silicone Republic. (2019). https://www.siliconrepublic.com/innovation/sc ience-communication-diversity-activism 


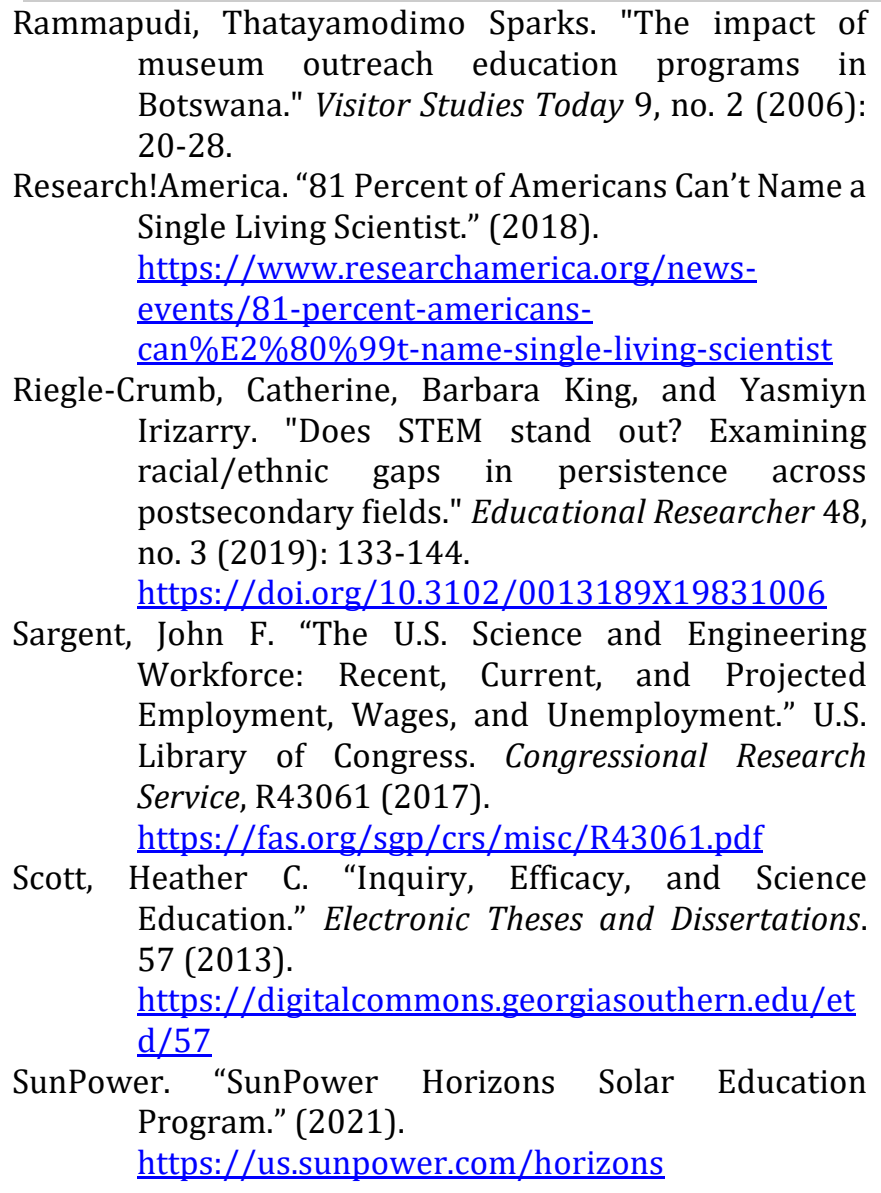
museum outreach education programs in Botswana." Visitor Studies Today 9, no. 2 (2006): 20-28.

Research!America. "81 Percent of Americans Can't Name a Single Living Scientist." (2018). https://www.researchamerica.org/newsevents/81-percent-americanscan\%E2\%80\%99t-name-single-living-scientist

Riegle-Crumb, Catherine, Barbara King, and Yasmiyn Irizarry. "Does STEM stand out? Examining racial/ethnic gaps in persistence across postsecondary fields." Educational Researcher 48, no. 3 (2019): 133-144. https://doi.org/10.3102/0013189X19831006

Sargent, John F. "The U.S. Science and Engineering Workforce: Recent, Current, and Projected Employment, Wages, and Unemployment." U.S. Library of Congress. Congressional Research Service, R43061 (2017). https://fas.org/sgp/crs/misc/R43061.pdf

Scott, Heather C. "Inquiry, Efficacy, and Science Education." Electronic Theses and Dissertations. 57 (2013).

https://digitalcommons.georgiasouthern.edu/et $\mathrm{d} / 57$

SunPower. "SunPower Horizons Solar Education Program." (2021).

https://us.sunpower.com/horizons

Thomas, Courtney L. "Assessing high school student learning on science outreach lab activities." Journal of Chemical Education 89, no. 10 (2012): 1259-1263. https://pubs.acs.org/doi/abs/10.1021/ed20032 $\underline{0 \mathrm{~g}}$

Ufnar, Jennifer A., Susan Kuner, and Virginia L. Shepherd. "Moving beyond GK-12." CBE-Life Sciences Education 11, no. 3 (2012): 239-247. https://www.lifescied.org/doi/10.1187/cbe.11$\underline{12-0119}$

Ufnar, Jennifer A., and Virginia L. Shepherd. "The Magic in The Classroom: A Twenty-Year Sustained Scientist in The Classroom Partnership Program." Journal of STEM Outreach 3.3 (2020): 1-15. https://doi.org/10.15695/istem/v3i3.06

United States Census. "2018 Public Elementary-Secondary Education Finance Data." (2018). https://www.census.gov/data/tables/2018/eco $\mathrm{n} /$ school-finances/secondary-educationfinance.html

University of Florida: Thompson Earth Sciences Institute. "Scientist in Every Florida School." (2021). https://www.floridamuseum.ufl.edu/earthsystems/scientist-in-every-florida-school//

Woolston, Chris. "University tenure decisions still gloss over scientists' public outreach." Nature News. (2018) https://doi.org/10.1038/d41586-018-06906-z

Vetri Velan is a Ph.D. candidate in physics at the University of California, Berkeley. His research focuses on detecting particles of dark matter, a mysterious substance making up $85 \%$ of the matter in the universe.

Rachel Woods-Robinson is a Ph.D. candidate at UC Berkeley researching new materials for solar cells. Alongside Elizabeth Case she co-founded Cycle for Science, an adventure-based science outreach organization.

Elizabeth Case is a Ph.D. candidate at Columbia University studying how glaciers form and flow, and a Scientist-in-Parks fellow at Grand Teton National Park. Along with Rachel Woods-Robinson, she co-founded Cycle for Science, a program that translates research into hands-on lessons for K-12 classrooms.

Isabel Warner is a Ph.D. candidate in microbiology at the University of Queensland. She studies bacterial genomes to find new targets for novel antimicrobials.

Andrea Poppiti is a middle school science teacher and an Ed.D. student at Rutgers University. She is interested in teachers' perceptions of and experiences implementing the Next Generation Science Standards.

Brian Abramowitz is a Ph.D. student at the University of Florida's College of Education. He studies the efficacy of partnerships between Earth systems scientists and K-12 teachers.

\section{Acknowledgments}

We sincerely thank Teresa Barnett, Tyler Chuck, and Eric Lee for providing valuable feedback based on their expertise in science policy, science education, and science outreach. We would also like to thank our editors for their comments, which greatly improved the manuscript. 